\title{
Impact of landuse on seasonal water quality at highland lake: a case study of Ringlet Lake, Cameron Highlands, Pahang
}

\begin{abstract}
A study to find the relationship between landuse development and seasonal water quality changes in highland lake, Ringlet Lake, Cameron Highland, Malaysia was carried out. The study found that most of the parameter analyzed in both seasons shows that the Ringlet Lake is Class III in the Water Quality Index Due to high percentage of cleared area, as indicated by individual type of landuse, pollutants were transported through Bertam and Ringlet river and eventually to the lake.
\end{abstract}

Keyword: Highland lake; Water quality analysis; Landuse impact; Seasonal variation; Water quality index 